\title{
BACHARÉIS QUE SE TORNAM PROFESSORES: INSERÇÃO E PRÁTICA PROFISSIONAIS DE ENGENHEIROS NO ENSINO SUPERIOR
}

\author{
S. H. S. C. Silva*, F.C.S. Souza** \\ * Instituto Federal de Educação, Ciência e Tecnologia da Paraíba \\ silviahspb@gmail.com \\ **Instituto Federal de Educação, Ciência e Tecnologia do Rio Grande doe Norte \\ chagas.souza@ifrn.edu.br
}

Submetido 25/01/2016 - Aceito 01/09/2017

DOI: $10.15628 /$ holos.2017.4033

\section{RESUMO}

Neste artigo, discutimos o exercício da docência por bacharéis com formação em engenharia. A pesquisa teve como cenário o curso de Engenharia Elétrica do Instituto Federal de Educação, Ciência e Tecnologia da Paraíba (IFPB), Campus João Pessoa. As questões norteadoras da pesquisa foram: por que engenheiros tornam-se professores? Como esses bacharéis professores avaliam suas primeiras experiências nessa profissão? Baseados no método autobiográfico, convidamos seis engenheiros professores do curso de Engenharia Elétrica do IFPB/João Pessoa para relatar sobre a inserção destes na docência e refletir quanto as suas experiências em sala de aula. As entrevistas abertas foram gravadas em áudio, transcritas e submetidas a análise de conteúdo. Os relatos dos entrevistados evidenciaram que estes tornaram-se docentes de forma não planejada, prevalecendo os aspectos contingenciais. Os entrevistados reconhecem a carência de uma formação pedagógica, mas não têm investido nesse tipo de formação na pós-graduação, de forma sistematizada. Destacamos a importância de mais estudos a respeito da docência exercida por egressos de cursos de bacharelados, mas também de políticas e incentivos à formação continuada desses sujeitos.

PALAVRAS-CHAVE: Engenheiros professores; Formação docente; Histórias de vida.

\section{GRADUATES WHO BECOME TEACHERS: INSERTION AND PROFESSIONAL PRACTICE OF ENGINEERS IN HIGHER EDUCATION}

\begin{abstract}
In this paper, we discuss the practice of teaching done by graduates with a background in engineering. The research took place at the course in Electrical Engineering from the Federal Institute Education, Science and Technology of Paraíba (IFPB), Campus João Pessoa. The guiding questions of the research were: why do engineers become teachers? How do these teachers with bachelor degree evaluate their first experience in this profession? Based on the autobiographical method, we invited six teachers engineers from the Course of Electrical Engineering IFPB/João Pessoa to report about their insertion into the teaching activity and reflect
\end{abstract}

about their experiences in the classroom. The open interviews were audio-recorded, transcribed and subjected to content analysis. The reports of respondents showed that they have become teachers in an unplanned way, prevailing the contingent aspects. The respondents recognize the lack of a pedagogical training, but have not invested in this type of training in the post graduate school, in a systematic way. We highlight the importance of more studies related to the teaching activity carried out by graduates of bachelor courses, but also of policies and incentives for continuing education of these professionals. 


\section{INTRODUÇÃO}

Em 2006, teve início um processo de expansão e interiorização da educação profissional pública federal, o qual se intensificou com a instituição da Rede Federal de Educação Profissional, Científica e Tecnológica e a criação dos Institutos Federais de Educação, Ciência e Tecnologia (IFs), por meio da Lei no 11.892, de 29 de dezembro de 2008.

A configuração da Rede Federal e a criação e expansão dos IFs, sobretudo na última década deste século, implicaram na contratação de um grande quantitativo de professores oriundos de cursos de bacharelados. Também foram ampliadas as oportunidades de criação, não apenas de novos campi, mas também de muitos cursos técnicos (de nível médio e superior) e de pósgraduação lato e strictu sensu.

É nesse contexto da expansão que teve origem o curso de Bacharelado em Engenharia Elétrica do Instituto Federal de Educação, Ciência e Tecnologia da Paraíba (IFPB/Campus João Pessoa), lócus desta pesquisa, cujas atividades letivas tiveram início no primeiro semestre de 2007.

Diante desse cenário, realizamos uma investigação cujo objetivo era discutir como esses bacharéis, mesmo sem terem passado por um curso superior de licenciatura, aderiram à profissão docente. Preocupou-nos ainda conhecer quais as primeiras experiências desses engenheiros professores no exercício da nova profissão.

Importa destacar que entendemos, como Imbernón (2011), que a profissão docente comporta um conhecimento pedagógico, entretanto este não é absoluto e se estrutura em uma gradação que vai desde o conhecimento comum ao especializado. Também chamamos a atenção para o fato de que os saberes docentes são plurais e construídos ao longo de uma trajetória de vida, como assinala Tardif (2011). Diante disso, compreendemos a docência como parte de um continuum no processo de desenvolvimento profissional dos professores (Marcelo, 2009).

\section{METODOLOGIA}

A metodologia se apoiou nas narrativas de histórias de vida de seis engenheiros professores do Bacharelado em Engenharia Elétrica (IFPB/João Pessoa), as quais foram gravadas em áudio, transcritas e submetidas à análise de conteúdo, conforme orientações de Bardin (2011). Ao narrar suas experiências formativas, esses professores refletiram sobre suas escolhas e como têm atuado em sala de aula, ou seja, discutiram a respeito do processo de constituição da docência. A escolha desse método se deu por este permitir, aos professores, momentos reflexivos e de autoavaliação, criando, assim, oportunidades de melhorias nas suas práticas. Além disso, percebemos nesse método uma possibilidade de percebermos a construção da docência como fruto de uma trajetória, um processo de construção lenta e gradual de saberes que vão desde a formação pessoal, familiar, até aqueles elaborados a partir das aprendizagens na academia.

Nesse aspecto, alinhamo-nos à síntese apresentada por Tardif (2011, p. 63) em um quadro no qual são apresentas as fontes de aquisição dos saberes (família, ambiente de vida, escolas primária e secundária, universidade, estágios, cursos de aperfeiçoamentos, livros, periódicos, sala de aula, experiências com os pares, dentre outros) e os modos como esses saberes se integram no trabalho docente (história de vida, formação e socialização pré-profissionais, práticas profissionais, além de outros). 
Este artigo está dividido em duas partes. Na primeira, apresentamos uma breve revisão de literatura a respeito da importância das narrativas de história de vida ${ }^{1}$ como estratégia metodológica para as pesquisas com foco na formação de professores. Em seguida, a partir das falas dos entrevistados, discutimos como se deu a inserção destes no exercício da docência.

\section{NARRATIVAS DE HISTÓRIAS DE VIDA E FORMAÇÃO DE PROFESSORES}

Conforme Benjamin (1993, p. 60), a narrativa "é uma forma artesanal de comunicação. Ela não está interessada em transmitir o 'puro em si' da coisa narrada como uma informação ou um relatório". A matéria da narrativa, portanto, é a própria experiência humana, e os instrumentos utilizados para a construção dessa história são as palavras.

Entendemos, com Larrosa (2002, pp. 21-25), que "a experiência é o que nos passa, o que nos acontece, o que nos toca". Nessa acepção ninguém pode aprender da experiência do outro a menos que esta experiência de algum modo seja revivida e tornada própria.

Nessa direção, a relação de reciprocidade entre a narrativa e a experiência precisa ser considerada e compreendida, pois "(...) assim como a experiência produz o discurso, este também produz a experiência. Há um processo dialético nesta relação que provoca mútuas influências" (Cunha, 1997, p. 1). Conforme essa autora, na pesquisa, a experiência vivida não é algo a captar, mas criada no próprio processo investigativo. Enquanto sujeitos históricos, construímo-nos a partir das relações que estabelecemos com o meio e os outros. É nessa rede de interdependência que o conhecimento é produzido e partilhado. Nesse sentido, são experiências formadoras de acordo com a intensidade do que nos atinge e alcança. Dessa forma, o relato não fala por si mesmo. Ele se organiza e depende da interação social estabelecida entre entrevistados e pesquisador.

Recorremos novamente às reflexões de Cunha (1997, p. 1): “As pessoas vão contando suas experiências, crenças e expectativas e, ao mesmo tempo, vão anunciando novas possibilidades, intenções e projetos". Nesse sentido, para a autora, experiência e narrativa se imbricam e se tornam parte da expressão de vida de um sujeito.

Para contar suas experiências o sujeito lança mão de sua memória, caso contrário a narrativa não existiria, daí a relação entre narrativa e memória. Conforme nos lembra Bosi (1994), a memória é uma experiência histórica indissociável das experiências peculiares de cada indivíduo e de cada cultura, tomada em toda sua diversidade estética, política, econômica e social.

Nessa perspectiva, rememorar acontecimentos da própria vida é sempre reflexão e autoconhecimento, pois toda experiência situa-se num contexto histórico e cultural, além de existir a possibilidade de se construir um olhar retrospectivo e prospectivo no tempo e sobre o tempo reconstruído não separado da investigação e da formação. Dessa forma, narrar uma trajetória de vida é atribuir sentidos e significados às experiências, pois aí se reconhece a subjetividade do sujeito como produção do saber.

\footnotetext{
1 Para Pineau (2006), o "movimento biográfico" gerou uma série de correntes e denominações: biografia, autobiografia, relato de vida, história de vida... Considerando esse entrelaçamento, utilizaremos doravante o termo "narrativa de história de vida", por este método se inserir dentro de metodologias qualitativas amplamente usadas pela Escola de Chicago, além de considerarmos esse termo mais adequado a essa pesquisa.
} 
$\mathrm{Na}$ pesquisa, o uso das narrativas visa analisar como os grupos sociais incorporam biograficamente os acontecimentos e as experiências de aprendizagem ao longo de uma trajetória de vida. Consideram-se fontes constituídas por histórias de vida: relatos orais, narrativas orais e escritas, fotos, memoriais, diários, cartas, entrevistas, escritas escolares e videográficas, configurando-as como objeto de investigação transversal nas Ciências Sociais e Humanas (Bueno, Chamlian, Sousa \& Catani, 2006).

Josso (2010) e Dominicé (2010) referem-se às autobiografias como "biografias educativas", ou seja, enquanto instrumentos de formação. Dessa concepção resulta uma consideração maior sobre o caráter formativo e uma nova perspectiva para a investigação educacional.

Nóvoa (1997) ressalta que, no processo de reflexão sobre sua trajetória de vida, o sujeito manifesta sua subjetividade e interpreta suas ações no plano individual e coletivo, na busca de significados para a construção de sua identidade profissional. Dessa forma, o método autobiográfico possibilita ao sujeito, por meio da narrativa, revelar seus anseios e expectativas ante a profissão e a própria vida. O autor ainda reforça que é sempre a própria pessoa que se forma, sendo ela o principal protagonista em seu processo de formação. Ou seja, o indivíduo torna-se ator do seu processo formativo ao realizar uma retrospectiva do seu percurso de vida.

Para Pineau (2010, p. 167), "as histórias de vida procuram estimular a autoformação, na medida em que o esforço pessoal de explicitação de uma dada trajetória de vida contribui para uma tomada de consciência individual e coletiva". Nesse sentido, o sujeito produz um conhecimento de si, dos outros e do cotidiano, revelando-se através da subjetividade, da singularidade, das experiências e dos saberes, questionando os sentidos de suas vivências e aprendizagens.

No Brasil, o "movimento autobiográfico" (Pineau, 2006) cresceu significativamente a partir dos anos 1990 e tem sua vinculação com pesquisas na área educacional, revelando as narrativas de histórias de vida numa perspectiva de formação e autoformação. As pesquisas internacionais despertaram interesse e, no Brasil, influenciaram a produção intelectual de muitos pesquisadores, a exemplo de Cunha (1997), Catani, Bueno, Sousa \& Souza (1997), Bueno et al (2006), dentre outros.

Conforme Ferrarotti (2010), o interesse crescente nos últimos anos pelo método biográfico se deve, em primeiro lugar, à necessidade de renovação metodológica na Sociologia. Em segundo lugar, pela exigência de uma nova Antropologia, pois as teorias sociais não davam conta das explicações macroestruturais, necessitando de uma maior proximidade com o campo psicológico individual do sujeito. Dessa forma, o método biográfico apresenta-se como uma opção para fazer a mediação entre as ações e a estrutura, ou seja, entre a história individual e a história social.

Em linhas gerais, de acordo com este autor, no que diz respeito às potencialidades do método biográfico, podemos considerar que, em sua especificidade, esta: atribui à subjetividade um valor de reconhecimento sem desconsiderar o sujeito e o investigador; situa-se para além da metodologia quantitativa e experimental; e constitui-se em um saber organizado, mas crítico em que estão presentes o singular e o universal da práxis humana.

Complementando esta lógica, as metodologias de pesquisa-formação estão articuladas à construção de uma história de vida, ao mesmo tempo em que vão ao encontro da "[...] subjetividade como modo de produção de saber e à intersubjetividade como suporte do trabalho interpretativo e de construção de sentidos para os autores das narrativas" (Josso, 2010, p.31). 
Josso (2010) considera que a metodologia de pesquisa-formação em narrativa de histórias de vida situa-se na constante preocupação de que os autores dos relatos cheguem a uma produção de conhecimento que faça sentido para eles, que se engajem, eles próprios, num projeto que os institua como sujeitos e que seja produtiva na medida do investimento que cada um faz em cada etapa do processo de reflexão. "A reflexão sobre aquilo que foi formador na minha vida e que me permite situar o que penso e faço reforça o espaço do sujeito consciencial capaz de se auto-observar e refletir sobre si mesmo" (Josso, 2010, p. 159-160).

Então podemos questionar: mas de que forma as narrativas possibilitarão aprendizagens sobre a profissão? Simplesmente porque têm na experiência sua base existencial, o que faz com que se articule saber-fazer e conhecimentos, funcionalidades, significação, técnicas e valores num espaço-tempo. A centralidade do sujeito confere a ele mesmo o papel de ator e autor de sua própria história (Josso, 2010).

A análise narrativa insere-se nos campos de investigação educacional, com grande força, por possibilitar a compreensão das práticas, motivações e escolhas que são amplamente calcadas na experiência humana. É possível identificar elementos que, em razão de sua riqueza formativa, precisam ser revitalizados, transformados ou reconstruídos tornando possível a compreensão do fenômeno educativo.

Não se pode perder de vista que, como meio de investigação e instrumento formativo, o método (auto)biográfico se traduz na produção de conhecimento: é essa dupla função que justifica cada vez mais a sua utilização no domínio das ciências da educação. Ao voltar-se para seu passado e reconstituir seu percurso de vida, o indivíduo exercita sua reflexão e é levado a uma tomada de consciência tanto no plano individual como no coletivo, considerados aqui como indissociáveis.

Conforme enfatiza Galvão (2005, p. 341):

O método da narrativa constitui uma forma simultaneamente rica, exaustiva e difícil de investigação. Rica em termos de experiência humana, pelas interações que se estabelecem entre todas as pessoas envolvidas, exaustiva pelo necessário aprofundamento e diversidade de estratégias para coleta de informação e difícil pela conjugação necessariamente coerente de todos os elementos passíveis de análise.

A importância da narrativa está no percurso vivido pelo sujeito e sua subjetividade. O que importa nos estudos é o processo, o caminho que ele percorreu, além dos elementos que contribuíram para a sua formação. Em uma história de vida, podem ser identificadas as continuidades e as rupturas, as coincidências no tempo e no espaço, os interesses e os quadros de referências presentes nos vários espaços do cotidiano. Todos esses elementos constituem um processo de reflexão, no qual o que interessa não é o resultado ou a quantidade de fatos que se rememora, mas os questionamentos, as descobertas, as inquietações, os sentidos de como se chegou até o contexto atual. Pode-se afirmar ainda que esse conjunto de experiências formam uma pluralidade de saberes que estarão presentes no fazer cotidiano do professor, como salienta Tardif (2011).

Ainda sobre o mérito das narrativas de histórias de vida, Burnier et al (2007, p. 356) enfatiza que: 
Ao analisarmos trajetórias de diversos sujeitos que exercem hoje uma mesma atividade profissional, pudemos perceber especificidades em seus relatos, que, além de falar de cada um deles como sujeitos individuais, evidenciaram experiências curiosamente recorrentes que permitem captar alguns importantes aspectos sociais e culturais dos processos identitários desses docentes, explicitando formas particulares de experimentar a condição docente e apontando pistas para pensar políticas e práticas para sua formação inicial e continuada.

É nessa perspectiva teórico-metodológica que a pesquisa aqui apresentada percorreu seu caminho. Buscamos uma metodologia que oportunize um espaço para que os seis engenheiros professores do Bacharelado em Engenharia Elétrica (IFPB/João Pessoa) relatem suas trajetórias de formação, conduzindo-os a uma reflexão de si e de suas experiências no contexto em que estão inseridos, e, ao mesmo tempo, fazer-nos conhecer e compreender como aqueles engenheiros se tornaram os professores que são hoje.

Entendemos com Bosi (2003, p. 49) que "muito mais que qualquer outra fonte, o depoimento oral ou escrito necessita de esforço de sistematização e claras coordenadas interpretativas". A partir dessa leitura, tornou-se um desafio interpretar as narrativas dos seis engenheiros professores, pois cada sujeito é único e só se pode compreendê-lo desde sua própria trajetória biográfica individual. Ao mesmo tempo, apresentam aspectos comuns, como, por exemplo, a graduação em Engenharia e a inserção no mesmo contexto histórico, espacial e profissional.

O quadro de análise interpretativo das narrativas dos seis engenheiros professores foi elaborado de um modo coerente com o objetivo geral da pesquisa e com o zelo em compreender, sem impor uma rigidez pré-estabelecida. Como pesquisadores, sentimos a necessidade de traçar um caminho para organizar a análise das narrativas. Para tanto, utilizamos alguns referenciais sobre a análise de conteúdo propostos por Bardin (2011). Para ela, a análise de conteúdo "[...] oscila entre os dois polos do rigor da objetividade e da fecundidade da subjetividade. Absolve e cauciona o investigador por esta atração pelo escondido, o latente, o não-aparente o potencial do inédito (do não dito), retido por qualquer mensagem" (p. 15).

\section{NARRATIVAS DE ENGENHEIROS PROFESSORES}

Segundo Bauman (2005), diante da complexidade do mundo do trabalho, as escolhas profissionais fazem parte da fluidez que constitui as sociedades. Isso nos coloca diante de outras opções, possibilitando encontrar novas significações para as nossas escolhas primeiras. Logo, a vida profissional na sociedade contemporânea não é linear, estável, permanente e resultante de uma única opção.

No que diz respeito à docência, a primeira etapa em relação ao projeto de "vir a ser professor" é a adesão, que, de acordo com Nóvoa (2007, p. 16), é um dos três AAA que sustentam o processo identitário desse profissional: "porque ser professor implica sempre a adesão a princípios e a valores, a adoção de projetos [...]." Os outros AA são ação: "escolha das melhores maneiras de agir" e autoconsciência: "tudo se decide no processo de reflexão que o professor leva a cabo sua própria ação" (p. 16).

Como esses AAA (adesão, ação e autoconsciência) têm se feito presentes na vida profissional dos seis engenheiros professores do curso de Engenharia Elétrica do IFPB, Campus 
João Pessoa? Embora esse questionamento não tenha sido o nosso problema de pesquisa, os depoimentos dos entrevistados contemplaram o debate proposto por Nóvoa (2007).

Iniciamos nossas entrevistas convidando aqueles sujeitos para um relato sobre as razões que os levaram à escolha da carreira docente. Ainda que as respostas tenham demonstrado que a docência não foi uma trajetória profissional planejada por todos, é possível perceber, nessas narrativas, certa intencionalidade, existindo razões objetivas e subjetivas acompanhando cada escolha.

No transcorrer da fala do engenheiro professor Correia, é possível evidenciar que, mesmo quando a primeira escolha profissional não foi para ele a docência, esta se coloca como forma de ressignificar a trajetória profissional, alterando-a e percorrendo outro caminho:

Ela [sua esposa] conseguiu um emprego na universidade e, quando vi aquele preparo de aula, eu percebi que era aquilo que gostava de fazer. Eu gostava de ensinar, mas até então não havia percebido isso. Eu era aquele que juntava o pessoal [colegas da época da graduação] para estudar e explicava como era que fazia e dizia que dava para fazer desse jeito e quando alguém não entendia eu arranjava um jeito diferente de ensinar. E comecei a perceber que eu gostava disso. [...] Larguei [um emprego] no final de 2007, pedi a exoneração e vim tentar a sorte. [...] Eu queria procurar alguma coisa e testar. Larguei para testar se eu gostava ou não de ensinar.

A lembrança de que gostava de ensinar, já na época da graduação, estava em via de validar-se mediante uma experiência de ensino, um "teste", possibilidade que se abriu em função da profissão da esposa, a quem atribuiu um valor. Esse fato evidencia o quanto uma carreira profissional (aqui, a profissão docente) é permeada por fatores e acontecimentos externos e passa por redimensionamentos.

Conforme esclarece Bolívar (2002), a carreira possui uma perspectiva objetiva, visto que possui uma série de condições e papéis claramente definidos. Entretanto, há também uma perspectiva subjetiva ou vivencial: "é a possibilidade de desenvolvimento graças à qual a pessoa vê sua vida como um todo e interpreta os diversos atributos, ações e coisas que lhe aconteceram" (Hughes, 1958 apud Bolívar, 2002, p. 76).

É essa dimensão subjetiva que encontramos na narrativa do engenheiro professor Ferreira:

Na indústria, quando chega meados de dezembro, ela demite por várias questões. E eu fui dentro dessa... Lembro que, na época, foram mais de 300 pessoas demitidas. [...] eu decidi que ia terminar o mestrado e doutorado, porque eu não queria estar mais naquele movimento de emprega e desemprega. [...] Decidi fazer alguma coisa que desse mais estabilidade. Chegou 2007, foi quando começou a aparecer mais concurso. [...] Mesmo sabendo que o salário podia ser pouco, baixo, na escola, mas eu não teria aquela sensação que tive lá [quando ficou desempregado].

Diante da experiência desagradável do desemprego, a docência, no caso de engenheiro, foi motivada pela possível estabilidade em um emprego público. Não passar novamente por isso foi mais significativo, para Ferreira, que o salário maior que receberia na indústria. 
Sem ter experenciado uma situação similar, mas aproveitando também a oportunidade dos concursos para bacharéis nos IFs, o engenheiro professor Barros optou pela docência no seguinte contexto:

No meu mestrado teve uma proposta de emprego. Eu fui à empresa e entreguei o meu currículo. Mas o meu perfil não era o esperado porque eu tinha mestrado e estava muito focado em uma área. Aí eu olhei assim: "É, já que corri para esse lado, então vou seguir agora". [...] Então, eu terminei o mestrado já entrando no doutorado. [...] Eu não vinha me preparando. Foquei muito no doutorado. Então, em nenhum momento eu fiquei pensando em docência até aparecer o concurso para cá, quando houve essa oportunidade, [...] emprego público com um salário bom e estabilidade... Quando eu terminasse o doutorado, iria terminar sem emprego, mas se eu ficasse no IF eu teria um futuro garantido. Então, foi uma coisa que me incentivou a ficar.

Nota-se a docência como algo não direcionado, não como um projeto profissional, tanto para Barros como para Ferreira. O que parecia ter sido planejado era trabalhar numa empresa. Como não foi possível para ambos, o serviço público tornou-se a melhor opção, pois garantiria estabilidade.

A escolha pela docência, para o engenheiro professor Evangelista, foi permeada por dúvidas iniciais entre seguir para o mundo empresarial ou destinar-se à docência. Idas e vindas, interrupções, rupturas entre empresa e a docência em instituições particulares marcaram essa etapa no início de sua vida profissional:

Depois de um tempo, voltar para o mercado como engenheiro ou partir para a área acadêmica? No meio do mestrado, eu me interessei em seguir a carreira acadêmica [...] mas queria voltar para o mercado. Tinha aquele gás para trabalhar no mercado. Mas, me alertei para dar aula em faculdades particulares. [...] Atentei a essa oportunidade de uma segunda carreira e [na época] estava havendo aquele "boom" de concursos com as expansões das faculdades privadas $e$ dos Institutos Federais. [...] No início, realmente seria dificultoso pelo baixo salário em relação ao mercado de engenharia. [...] Eu pensei muito bem se deixaria para voltar ao mercado, pois ele paga melhor para quem tem uma determinada formação, uma determinada experiência.

Entendemos, a partir da fala desse professor, que essa "segunda carreira" passou por transformações, quando, na metade do seu mestrado, foi vislumbrada a possibilidade de seguir carreira acadêmica na docência, mesmo ainda expressando o desejo de continuar no mundo empresarial. Parece-nos que Evangelista encontrou uma alternativa temporária enquanto se decidia sobre o que iria realmente fazer de sua vida profissional. $\mathrm{O}$ aspecto financeiro, a dimensão objetiva (Bolívar, 2002), até aquele momento, estava sendo levado em consideração.

A influência de colegas na época em que fazia o mestrado foi um fator motivador para que o engenheiro professor Andrade escolhesse a docência em uma instituição particular.

Um dos colegas que também estava fazendo mestrado tinha passado num concurso interno para ser professor. [...] Tive a experiência de uma primeira aula com uma banca e fui contemplado. Eu ficava pensando: esse negócio não era para mim, não. Mas aí eu olhei para um lado, olhei para o outro, e sabe de uma coisa, 
eu vou encarar esse negócio de maneira séria mesmo e vamos ver no que é que dar.

Apesar de parecer acreditar que não seguiria inicialmente o que chama de "negócio da docência", resolveu passar pela experiência, pois parece que não havia outra opção naquele momento. Melhor seria ver "no que é que vai dar". Novamente a docência sem um planejamento, uma obra do acaso, uma aposta.

A escolha pela docência para a engenheira professora Duarte teve outra razão. Ela se viu motivada em seguir outro caminho profissional a partir de insatisfações vividas na empresa privada, como nos revela a professora:

Eu estava no final de um o projeto e fiquei três meses sem receber nada [bolsa de pesquisa] e não apareceu concurso. Por isso, eu fui parar na empresa. [...] Me adaptei rápido, aprendi muita coisa, só que vi que a satisfação já não era a mesma do início. Com aquele ritmo, fazendo a mesma coisa, era o mesmo raciocínio. [...] Caí numa rotina, sempre a mesma coisa. Aí eu comecei a estudar para ser docente.

Mas, antes da admissão nesta empresa privada, Duarte já aguardava oportunidade para concursos. Como não surgiu, optou pela proposta mais segura naquele momento. Parece que a intenção primeira de seguir a carreira docente foi retomada depois de certo tempo, ficando explícito no seu relato "comecei a estudar para ser docente". Assim, estão presentes, na narrativa de Duarte, mudanças ou alterações em seu percurso profissional, retomada de projetos iniciais, revelando a não linearidade que permeia uma dada trajetória de vida, denotando um claro significado de escolha, não como uma obrigação ou por força de uma contingência externa.

Isso implica entendermos que a centralidade do sujeito confere a ele mesmo papel de ator e autor da própria história (JOSSO, 2010). Podemos considerar esse acontecimento como uma descontinuidade, mas que ensejou mudança nesse percurso profissional por opção própria, como no caso de Duarte.

Percebemos uma modificação na trajetória profissional, mais acentuada, nos relatos dos engenheiros professores Ferreira, Evangelista, Correia e Duarte. Estes iniciaram-se profissionalmente como engenheiros em empresas privadas, e, somente após um tempo, fizeram a adesão à docência, em função de razões diferentes. Nessa direção, Bolívar (2002, p. 80) ressalta que "na trajetória de vida, [...] certos acontecimentos que produzem um 'corte' ou 'trauma' na carreira ou socialização profissional e, por isso, contribuem [...] para modificar/inverter a trajetória de vida ou a identidade profissional".

No caso da profissão docente, Bolívar (2002) enfatiza que o início é marcado por aprendizagens intensas. Nesses primeiros anos, os professores são iniciantes e, em muitos casos, podem ainda estar lutando para estabelecer sua própria identidade pessoal e profissional. Significa também um momento de socialização, pois é durante as práticas de ensino que começam a conhecer a cultura escolar. Mas é durante o período de inserção profissional que essa socialização se produz com maior intensidade. Nesse momento, os novos professores aprendem e interiorizam normas, valores e condutas que caracterizam a cultura escolar na qual se integram. 
O estudo de Huberman (2007), sobre o percurso profissional ou ciclo de vida dos professores é considerado um clássico na área. Mesmo referindo-se a professores secundários e da cultura francesa, o modelo, por ele apresentado, contempla percursos possíveis de serem percorridos por professores universitários da cultura brasileira. Visando abarcar percursos variados, ele apresenta uma sucessão de anos combinados com fases que podem apresentar mais de uma temática, permitindo entradas e saídas diversificadas ao longo da carreira, rompendo, assim, com a ideia de modelo linearmente construído.

Huberman (2007) observa que o início da profissão é o período em que o professor se defronta com dois sentimentos: a sobrevivência, caracterizada pela luta contra a desistência dessa profissão ao se deparar com tantas adversidades; e a descoberta, quando o professor se descobre como profissional. Para este autor, é o segundo sentimento que permite a permanência do professor na profissão, superando o primeiro.

Nos relatos a seguir, algumas manifestações de choque com a nova realidade profissional foram expostas pelos entrevistados:

No primeiro semestre, eu só tive uma disciplina. Mas o lado ruim é que eu ia entrar no lugar de um professor que já tinha começado a dar a disciplina. E era um dos melhores professores que eles tinham. Fiquei numa situação muito ruim. Pegar uma disciplina que já está andando é algo muito ruim. [...] Eu passei um aperreio no começo. [Depois] ministrei uma grande quantidade de disciplinas diferentes. Muito grande, mesmo! E até muitas disciplinas ao mesmo tempo, também. Então, realmente as coisas iniciais foram muito ruins. (Engenheiro professor Andrade)

Peguei muita disciplina, em torno de seis disciplinas diferentes. E recém-chegado no IF, não fiz mais nada a não ser preparar aulas e estudar para dar aulas. (Engenheiro professor Ferreira)

Um aspecto que nos chama atenção na narrativa de Andrade é a recorrência do adjetivo "ruim" durante boa parte de seu relato. A impressão que temos é que para ele não houve muita coisa boa nessa fase inicial, pois foi "ruim" assumir uma disciplina que já estava em andamento, ruim "entrar no lugar de um professor que já tinha começado a dar a disciplina", e que "era um dos melhores", além de ser ruim a "grande quantidade de disciplinas e diferentes". Já para Ferreira, a experiência de ter várias disciplinas, foi vista de forma mais pragmática: "não fiz mais nada, a não ser preparar aulas e estudar para dar aulas".

Ao lembrar-se da experiência do início da docência, a engenheira professora Duarte reflete além de si mesma e, talvez para não se sentir tão sozinha diante das dificuldades iniciais, considera que outros colegas possam ter passado também pela mesma situação:

A maior dificuldade, que não deve ser só minha, é preparar aulas para a disciplina. Nos primeiros seis meses foi um sufoco. Eu trabalhava muito mais do que na empresa, porque você tem que ler os livros, preparar aulas, fazer resumos, colocar em slides, fazer atividades práticas... Principalmente a parte prática. Eu vou fazer qual prática para refletir esse assunto? Que equipamento eu vou usar? Então, foi bem corrido. E teve uma época que fiquei com carga horária muito alta, 22 horas/aulas. Então a grande dificuldade era a preparação da aula entre a teórica e a prática. (Engenheira professora Duarte). 
Na narrativa de Duarte, percebemos a preocupação com o preparo das aulas teóricas e, principalmente, com as práticas nos laboratórios. Ela lamenta também acerca da alta carga horária em detrimento da falta de tempo para o preparo dessas aulas, chegando a observar que o volume de trabalho era maior que o da empresa onde atuava anteriormente. Em contrapartida, a descoberta, comentada por Huberman (2007), traduz dimensões positivas relativas ao entusiasmo, ao encanto da novidade, pois, no início, "tudo era muito novo" para essa professora.

A situação enfrentada por Duarte é a mesma deparada pela maior parte dos bacharéis que tornam-se professores. Eles não iniciam a carreira docente conhecendo as discussões sobre teorias e práticas pedagógicas, matrizes curriculares, Projetos Político-Pedagógicos... Assim, segundo Souza e Nascimento (2013, p. 416), eles, "[...] ao iniciarem a docência, [...] chegam com esses dispositivos previamente aprovados, restando-lhes apenas o papel de executar as ementas das disciplinas elaboradas anteriormente à sua admissão [...]". Nesse novo contexto, que conhece apenas enquanto ex-aluno, é necessário buscar caminhos para a superação dos entraves.

O engenheiro professor Barros faz um balanço dessa fase inicial:

No primeiro semestre, eu me preocupava para não errar, saber tirar a dúvida de um aluno. Foi um estágio muito difícil para mim. [...] Eu não tinha tempo de me preparar para a aula. Então acho que tive uma baixa eficiência no primeiro ano motivada pelo tempo de me preparar para aula e não ter experiência anterior de lecionar. Eu dizia: "não era o momento de estar na docência, eu tinha que terminar o doutorado ...". E eu ia prestar outro concurso. A minha vida ficou muito difícil, muito dividida. Eu não conseguia me desapegar [...] da família, da namorada, de todos esses problemas. [...] e a semana ficava muita corrida para mim. O meu orientador não me incentivava muito. Achei que ele queria números, publicação de artigos, prazos, ele se preocupava com isso. (Engenheiro professor Barros)

O início da atividade docente, para Barros, foi permeado por vários problemas. Mas, ao mesmo tempo em que os destaca, esse professor faz pertinentes reflexões sobre seu desempenho profissional, motivado, dentre outras coisas, pelo produtivismo que predomina na academia. Merece ressalte o termo "baixa eficiência", usado por ele no momento de avaliação do seu trabalho. Neste ponto, retomamos o valor da narrativa para a reflexão e a autoformação do sujeito:

Sem um trabalho especificamente centrado nas tomadas de consciência de nossas ideias, nossas crenças, nossas convicções, etc., para as quais o trabalho biográfico sobre as histórias narrativas de formação é uma das vias possíveis, nós continuaremos profundamente prisioneiros de nossos destinos socioculturais e sócio-históricos. (Josso, 2007, p. 436)

O engenheiro professor Correia comenta o seu início na nova profissão: "A primeira coisa que vem é lembrar dos professores que eu mais gostava e tentar replicar o que eles faziam. [...] é a primeira defesa que a gente tem". Desta fala entendemos que lidar com o início da trajetória profissional parece ter sido compensado pela lembrança dos professores que mais admirava, tomando-os como modelos inspiradores. O termo "defesa" parece sugerir algo que vem para amenizar a tensão diante do enfrentamento do desconhecido. 
Com relação a essa "formação" para a prática docente, sem necessariamente ter um diploma para isso, Alves (2008, pp. 136-137) é enfática:

[...] antes de termos o direito legal de sermos professores/professoras, "aprendemos o ofício" nas centenas de aulas assistidas durante toda a trajetória que nos levou a "escolher a profissão" e em narrativas do exercício profissional feitos por docentes nossos conhecidos ou com quem vamos tendo aulas [...]. (Grifos da autora)

A necessidade de sobreviver no novo meio e o enfrentamento da complexidade do trabalho docente provocaram a urgência em resolver uma série de adversidades. Ao ingressar na docência, diante das tensões iniciais, esses engenheiros encontraram estratégias de sobrevivência ou respostas positivas para resolver os problemas que surgiam. É o que vemos nos relatos abaixo:

[...] eu comecei a juntar os conteúdos e a distribuir melhor o meu tempo para tentar gastar um pouco mais de tempo preparando aula. [com o tempo] fui aperfeiçoando o método. Eu percebi que o pessoal [os alunos] começou a fazer mais perguntas. (Engenheiro professor Andrade)

Eu fui perguntando aos professores que eu conheci aqui [no IFPB], fui pesquisando. Tive que estudar em muitos sábados e domingos. Olha, os primeiros seis a oito meses foram de muita dedicação para preparar essas aulas. Então você tem que ter todo um preparo, você tem que fazer a prática antes. Na hora da aula, já tenho que ter feito. Já ter anotado os resultados. (Engenheiro professor Duarte)

O que podemos destacar das falas de Andrade e Duarte é que, para superar as dificuldades, foi necessário um significativo investimento em muitas horas de estudo, inclusive finais de semana. Prática idêntica fizeram Ferreira e Barros, respectivamente: “(...) não fiz mais nada a não ser preparar aulas e estudar para dar aulas"; "Era lendo livros, lendo, lendo, lendo... estudando bastante para ter segurança".

Diferente de Duarte, Evangelista, embora tenha encontrado uma justificativa, optou por não procurar ajuda junto aos seus colegas mais experientes da instituição. Ele reconheceu a lacuna causada pela ausência de uma formação pedagógica e ainda a necessidade de auxílio: "No início, tive muita dificuldade, inclusive com o relacionamento com os alunos... [...] creio até hoje que por essa falta de formação pedagógica. Vi que precisava de ajuda, mas nem os próprios professores, meus colegas, têm essa formação". Diante disso, resolveu as limitações iniciais por conta própria, solitariamente: "Comecei a buscar informação por mim mesmo, o que, muitas vezes, é difícil. Você está em um campo em que não se tem ninguém para compartilhar conhecimento algum".

A preocupação em se adaptar à nova realidade, demonstrada nas narrativas dos engenheiros professores, caminha no sentido do seu desenvolvimento profissional, concebido por Imbernón (2011, p. 47) como "qualquer intenção sistemática de melhorar a prática profissional, crenças e conhecimentos profissionais, com o objetivo de aumentar a qualidade docente, de pesquisa e de gestão".

A troca de experiências com os colegas de trabalho é um momento de socialização e faz parte do desenvolvimento profissional dos professores. Mas, muitas vezes, existe uma "[...] cultura profissional marcada pelo isolamento e pelas dificuldades para aprender com os outros, na 
qual é malvisto pedir ajuda ou reconhecer dificuldades", como destaca Marcelo (2010, p. 22). Em seguida, o autor explica: "o isolamento está favorecido pela arquitetura escolar que organiza as escolas em módulos independentes, assim como pela distribuição do tempo e espaço e pela existência de normas de autonomia e privacidade entre os professores".

Apesar de constatar a "falta de formação pedagógica" e de admitir que necessitou de ajuda, o engenheiro professor Evangelista não realizou sua pós-graduação (mestrado e doutorado) na área de educação e nem frequentou cursos direcionados à complementação pedagógica, embora tenha presença efetiva no Congresso Brasileiro de Educação em Engenharia (COBENGE), desde 2007, mas com artigos mais específicos da área de engenharia.

Um comentário importante a respeito das práticas dos engenheiros professores é feito por Bazzo (2011, p. 13): “(...) os engenheiros-professores acabam aprendendo a ser docentes, quando isso acontece de fato, pela própria experiência, com um esforço solitário, sem os benefícios de uma sistematização consciente de procedimentos". Ainda, para este autor, o modelo de profissionalização eminentemente tecnicista, apontado para o fazer, o produzir e o utilizar, deve ser urgentemente repensado. Isso não implica em desconsiderar a capacitação técnica, já que o ensinar está diretamente ligado aos conhecimentos específicos do professor. As questões históricas, epistemológicas ou mesmo aquelas referentes a uma teoria do conhecimento têm sido consideradas como não pertencentes ao universo possível da engenharia.

$\mathrm{Na}$ pesquisa realizada por Buonicontro (2001), entre as alternativas levantadas pelos professores para enfrentar as dificuldades apontadas no exercício da docência, não foram feitas referências a suportes pedagógicos ou espaços institucionalizados de formação continuada, em que os mesmos poderiam ressignificar a sua prática, compartilhar experiências e construir uma identidade docente. Segundo a autora, revela-se, nestas práticas, o trabalho solitário e individualizado da docência.

A investigação de Loder (2002) evidenciou que alguns professores entrevistados, ao perceberem a insuficiência das ações tradicionais de ensino, intuitivamente buscaram alternativas. Porém, tal prática poderia ter seus efeitos potencializados se devidamente refletida, sistematizada e compartilhada entre seus pares, num processo contínuo de formação para a docência, pois é no cotidiano da atividade docente que esses profissionais constroem suas práticas e se tornam professores.

Segundo Castanho (2002), para os professores envolvidos em sua pesquisa, a formação e a inovação pedagógica, ainda que reconhecida como necessárias, aparecem relacionadas à emergência do professor como tutor, ao emprego de novas tecnologias, mesmo que na prática se dê de forma tradicional e não inovadora do ponto de vista pedagógico.

Já a pesquisa de Álvares (2006) revelou que, inicialmente, grande parte dos professores reconhece a importância da formação pedagógica para o exercício da docência, embora tenha uma visão dessa formação restrita às metodologias e técnicas de ensino, atribuída pela autora ao fato de a formação profissional na engenharia não contemplar aspectos pedagógicos que poderiam subsidiar a atividade docente.

As limitações impostas pela falta de uma formação para a profissão docente vão, aos poucos, esvaecendo. Nesse sentido, Oliveira (2011) ressalta que ser bacharel e professor, mesmo tendo os problemas que já mencionamos, é um elemento significativo para a formação dos alunos no ensino superior, pois estes profissionais, alguns já com experiências no mundo do trabalho, 
trazem para a sala de aula contribuições importantes para o desenvolvimento acadêmico daqueles. Essa realidade está presente em duas narrativas de nossos entrevistados:

Eu utilizo muito a minha experiência profissional. Adapto aquilo que vimos na Engenharia com aquilo que realmente se aplica. Às vezes a escola não faz um link muito forte com a indústria. Então, é importante trazer um pouco da indústria para dentro do laboratório da escola. O aluno aprende vendo mais do que você falando. (Engenheiro professor Ferreira)

Gosto muito desse mundo empresarial. Mas eu gosto muito de dar aula. Já que eu gosto das duas coisas, eu trouxe para dentro da minha aula. Eu preparo as minhas aulas voltadas para como os alunos resolverão os problemas e como a empresa vai cobrar. Abrir uma empresa para descobrir como é que funciona, tentar participar para saber como é que a gente se insere, quais são os mecanismos de captação de recursos... são dúvidas que os alunos têm, eles querem saber disso. (Engenheiro professor Correia)

Nas falas de Ferreira e Correia, estão presentes a necessária aproximação da escola e empresa, a aplicabilidade dos recursos da engenharia, além da discussão nas aulas sobre aspectos do mundo do trabalho.

Todavia, consideramos que a experiência profissional do engenheiro professor, apesar de trazer ganhos para a instituição, não pode ser vista como condição sine qua non para o bom andamento de uma aula. Existem outras alternativas para se "trazer um pouco da indústria" para dentro da sala de aula, tais como convênios de projetos de pesquisas com empresas regionais e nacionais. Outras opções são metodologias de estudo de caso e abordagem baseada em projetos, por exemplo.

Parece-nos que os seis engenheiros professores, apesar das dificuldades enfrentadas no início da docência, têm conseguido superar, cada um a seu modo, as dificuldades. Para Huberman (2007), as pessoas que iniciam bem, embora passem por momentos dificultosos, parecem prosseguir razoavelmente bem. No entanto, as que começam com dificuldades não têm por que terminar mal. O "bom começo", associado à eficiência e ao domínio pedagógico da tarefa docente, parece antecipar uma última fase ou desenlace "satisfatório". É claro que aqui nesta pesquisa não almejamos predizer o futuro desses professores nem nos antecipar a isso, mas concordamos que é uma lógica aceitável.

Frente às narrativas dos seis engenheiros professores entrevistados, percebemos que a inserção profissional na docência, como reconhece Marcelo (2010, p. 28): "é um período de tensões e aprendizagens intensivas em contextos geralmente desconhecidos e durante o qual os professores iniciantes devem adquirir conhecimento profissional além de conseguirem manter certo equilíbrio pessoal". Daí a inserção na docência ser vista como parte de um continuum no processo de desenvolvimento profissional dos professores, sendo um período diferenciado no caminho para se tornar professor. 


\section{CONSIDERAÇÕES FINAIS}

Os engenheiros professores entrevistados tornaram-se professores, sobretudo, por uma combinação de acontecimentos ou eventos que os conduziram a isso: desemprego, busca por estabilidade profissional no serviço público, oportunidade dos concursos nos IFs, insatisfações com o trabalho na empresa privada, dentre outros motivos.

As primeiras experiências como professores foram permeadas por redimensionamentos entre a profissão de engenheiro e a docência, o que, naturalmente, foram acompanhadas de tensões iniciais, visto que lidar com o novo e desconhecido gera angústia, receio, preocupação, dúvida e insegurança. Entretanto, esses profissionais encontraram estratégias de sobrevivência e enfrentamento de suas limitações. Pareceu-nos que, apesar disso, a experiência se desenvolveu de forma satisfatória, pois em nenhum relato vimos comentários que demonstrasse a desistência da profissão.

As trajetórias pessoal e acadêmica desses engenheiros professores agiram no sentido de compor os seus saberes (Tardif, 2011) e o seu desenvolvimento profissional enquanto docentes (Imbernón, 2011; Marcelo, 2009). Não foram percursos lineares, mas construídos e reconstruídos em meio a dúvidas, redimensionamentos, retrocessos, compartilhamentos com as pessoas de suas convivências, como alunos e colegas, mas também em meio a momentos de solidão e isolamento.

Entretanto, mesmo lidando de forma satisfatória com as dificuldades, a conclusão que temos, a partir dos seus relatos, é que houve certa despreocupação por parte dos entrevistados, em realizar cursos de capacitação voltados para a área da educação, o que os ajudaria no desenvolvimento de suas práticas pedagógicas.

Também alertamos para a necessidade das instituições de ensino participar efetivamente da integração e do acompanhamento dos professores ingressantes. No caso do IFPB, ainda não existe uma política institucionalizada de formação pedagógica para docentes no início da carreira. Acreditamos que um projeto de formação pedagógica não é apenas responsabilidade de pedagogos dessa instituição, mas também um compromisso das diretorias, chefias de departamento e coordenadores de cursos. Dessa forma, ressaltamos que as instituições de ensino precisam se constituir em um espaço coletivo de formação e desenvolvimento profissional docente, ampliando e proporcionando momentos para trocas de experiências entre os pares, por exemplo, em grupos de estudo.

\section{REFERÊNCIAS}

Álvares, V. O. M. (2006). O docente-engenheiro frente aos desafios da formação pedagógica no ensino superior. Dissertação de Mestrado, Universidade Federal de Uberlândia, UberlândiaMG, Brasil.

Alves, N. (2008). Nós somos o que contamos: a narrativa de si como prática de formação. In: Souza, E. C. \& Mignot, A. C. V. (Orgs). Histórias de vida e formação de professores (pp. 131146). Rio de Janeiro: Quartet: FAPERJ.

Bardin, L. (2011). Análise de conteúdo. São Paulo: Edições 70.

Bauman, Z. (2005). Identidade: entrevista a Benedetto Vecchi. Rio de Janeiro: Jorge Zahar. 
Bazzo, W. A. (2011). Ciência, tecnologia e sociedade e o contexto da educação tecnológica. 2. ed. Florianópolis: UFSC.

Benjamin, W. (1993). Obras escolhidas: magia e técnica, arte e política. São Paulo: Brasiliense.

Bolívar, A. (2002). Profissão professor: o itinerário profissional e a construção da escola. São Paulo: EDUSC.

Bosi, E. (1994). Memória e sociedade. São Paulo: Companhia das Letras.

Bosi, E. (2003). O tempo vivo da memória: ensaios de psicologia social. São Paulo: Ateliê Editorial.

Bueno, B. O., Chamlian, H. C., Sousa, C. P. \& Catani, D. B. (2006). Histórias de vida e autobiografias na formação de professores e profissão docente (Brasil, 1985-2003). Educação e pesquisa, $32(2), 385-410$.

Burnier, S. et al. (2007). Histórias de vida de professores: o caso da educação profissional. Revista Brasileira de Educação, 12(35), 343-358.

Buonicontro, C. M. S. (2001). O processo de construção da prática pedagógica do engenheiroprofessor: um estudo no curso de Engenharia Mecatrônica da PUC Minas. Dissertação de Mestrado, Pontifícia Universidade Católica de Minas Gerais, Belo Horizonte, Brasil.

Castanho, M. E. L. M. (2002). Docência e inovação na área de Ciências Exatas e Engenharias. Revista de Educação PUC-Campinas, 12, 51-60.

Catani, D. B., Bueno, B. O., Sousa, C. P. \& Souza, M. C. C. (Org.). (1997). Docência, memória e gênero: estudos sobre formação. São Paulo: Escrituras.

Cunha, M. I. (2011). Conta-me agora! as narrativas como alternativas pedagógicas na pesquisa e no ensino. Revista da Faculdade de Educação, (23)1-2.

Dominicé, P. (2010). O processo de formação e alguns se seus componentes relacionais. In: Nóvoa, A. \& Finger, M. O método (auto) biográfico e a formação. (pp. 81-96). Natal: EDUFRN; São Paulo: Paulus.

Ferrarotti, F. (2010). Sobre a autonomia do método biográfico. In: Nóvoa, A. \& Finger, M. $O$ método (auto) biográfico e a formação. (pp. 31-58). Natal: EDUFRN; São Paulo: Paulus.

GALVÃO, C. (2005). Narrativas em educação. Ciência \& Educação, (11)2, 327-345.

Huberman, M. (2007). O ciclo de vida profissional dos professores. In: Nóvoa, A. (Org.). Vidas de professores. (pp. 31-62) 2. ed. Porto: Porto Editora.

Imbernón, F. (2011). Formação docente e profissional: formar-se para a mudança e a incerteza. São Paulo: Cortez.

Josso, M. (2007). A transformação de si a partir da narração de histórias de vida. Educação, (30)3, 413-438).

Josso, M. (2010). Experiências de vida e formação. Natal: EDUFRN; São Paulo: Paulus.

Larrosa, J. (2002). Notas sobre a experiência e o saber de experiência. Revista Brasileira de Educação, 19, 20-28.

Loder, L. L. (2002). Epistemologia versus pedagogia: o locus do professor de engenharia. Dissertação de Mestrado, Faculdade de Educação. Universidade Federal do Rio Grande do Sul. Porto Alegre, Brasil. 
Marcelo, C. G. (2009). Desenvolvimento profissional docente: passado e futuro. Sísifo, 8, 7-22.

Marcelo, C. G. (2010). O professor iniciante, a prática pedagógica e o sentido da experiência. Revista brasileira de pesquisa sobre formação de professores, (2) 3, 11-59.

Nóvoa, A. (1997). Formação de professores e profissão docente. In: Nóvoa, A. Os professores e sua formação. Lisboa: Nova Enciclopédia, 1997. p. 15-34. . (2007). Os professores e as histórias da sua vida. In: (Org.). Vidas de professores. (pp. 11-30). Porto: Porto Editora, 2007.

Oliveira, V. S. (2011). Ser bacharel e professor: sentidos e relações entre o bacharelado e a docência universitária. Tese de Doutorado em Educação, Centro de Ciências Sociais Aplicadas, Universidade Federal do Rio Grande do Norte, Natal, Brasil.

Pineau, G. (2006). As histórias de vida em formação: gênese de uma corrente de pesquisa-açãoformação existencial. Educação e pesquisa, (32)2, 329-343.

Pineau, G. (2010). A autoformação no decurso da vida: entre a hetero e a ecoformação. In: Nóvoa, A. \& Finger, M. O método (auto) biográfico e a formação. (pp. 97-118). Natal: EDUFRN; São Paulo: Paulus.

Souza, F. C. S.; Nascimento, V. S. O. (2013). Bacharéis professores: um perfil docente em expansão na Rede Federal de Educação Profissional e Tecnológica. In: Moura, D. H. (Org.). Produção de conhecimento, políticas públicas e formação docente em educação profissional. (pp. 409434). Campinas: Mercado das Letras.

Tardif, M. (2011). Saberes docentes e formação profissional. Petrópolis: Vozes. 